\title{
Visual acuity in patients with retinitis pigmentosa
}

\author{
Alruwaili I.Y ${ }^{1}$, Vanishri A ${ }^{2}$, Ashok Kumar ${ }^{3}$ \\ ${ }^{1}$ Dr. Ibtisam Yunus Alruwaili, OphthalmologyResident, ${ }^{2}$ Dr. Vanishri Ashok, Lab Registrar, Department of \\ Pathology, ${ }^{3}$ Dr. Ashok Kumar, ENT specialist; all authors are affiliated with King Fahad Hospital, Saudi \\ Arabia.
}

Address for Correspondence: Dr. Vanishri Ashok, Email: Vaniashok_thanks@yahoo.co.in

\begin{abstract}
Objective: The present study is taken up to learn the visual acuity in patients with retinitis pigmentosa (RP). Methods: The current study was conducted in thirty male and female patients with in age group of 30-50 years and thirty age matched controls with retinitis pigmentosa. Vision testing was conducted by trained optometrician. Visual acuity was tested for distance vision using Snellen's test type placed at a distance of 6 meters from the student and near vision using near vision test type with the student holding the chart in his/her hand at a distance of approximately $30 \mathrm{cms}$ from the face. Data was analyzed by SPSS 20.0. Statistical test used are student $t$ test. $\mathrm{P}$ value less than 0.05 was considered significant. Results: There was no significant difference between cases and controls in demographic data. Decline in the visual acuity was more prevalent in cases when compared to controls.Conclusion: We have observed decline in the visual acuity in the patients with retinitis pigmentosa. We recommend further detailed studies in this area.
\end{abstract}

Key words: Visual acuity, Retinitis pigmentosa, Eye disorders

\section{Introduction}

Retinitis pigmentosa (RP) a hereditary, progressive disease associated with night blindness and visual field defects Side vision) noticed in midperipheral area. The disease not only affects rod photoreceptors but also leads to the gradual degeneration of foveal cone photoreceptors further causing peripheral visual field restriction [1]. In short in RP, the rod cells and eventually the cone cells stop working, causing vision loss. The quality of vision is not affected in the early stage of RP but the field of vision is reduced.

There are several ways in practice like focal macular electroretinogram (fmERG), best-corrected visual acuity (BCVA), contrast visual acuity (CVA) and central visual field to assess the central visual function in RP. Visual acuity (VA) in ideal conditions is used to evaluate the maximum VA. Prior to the VA loss if there is any minute decrease in visual function can be evaluated by CVA [2]. Certain studies stated that even mild VA losses show reduced CVA and contrast sensitivity

Manuscript received: $20^{\text {th }}$ April 2017

Reviewed: $30^{\text {th }}$ April 2017

Author Corrected; $10^{\text {th }}$ May 2017

Accepted for Publication: $18^{\text {th }}$ May 2017
(CS) measurements in RP patients [3,4,5,6,7].As it is known that there is no therapy to cure RP, despite the lack of treatment it is very important for the patients to have regular eye check-ups as the RP patients are prone to other type of eye problems that can further effect the general population too. Regular visits to an RP specialist can also make you aware of current advances as we learn more about RP and treatments that may help you.

\section{Aims and Objectives}

The present study is taken up to learn the visual acuity in patients with RP.

\section{Materials and Methods}

Study design: Case control study

Setting: The study was conducted at King Fahad Hospital, Saudi Arabia

Participants: The current study was conducted in thirty male and female patients with retinitis pigmentosa in age group of 30-50 years and thirty 


\section{Original Research Article}

age matched controls. Vision testing was conducted by trained optometrician.

Visual acuity was tested for distance vision using Snellen's test type placed at a distance of 6 meters from the student and near vision using near vision test type with the student holding the chart in his/ her hand at a distance of approximately $30 \mathrm{cms}$ from the face [8].

The following criteria was used for selecting patients.
Inclusion criteria: Patients diagnosed with retinitis pigmentosa, willing participants with in the age group of 30-50 years were included in the study.

\section{Variables}

Visual acuity: Visual acuity was measured by standard methods mentioned in the literature.

Statistical analysis- Data was analyzed by SPSS 20.0. Statistical test used are student $t$ test. $P$ value less than 0.05 was considered significant.

\section{Results}

Table 1 presents demographic data of the participants. There was no significant difference between cases and controls in demographic data. Decline in the visual acuity was more prevalent in cases when compared to controls (table 2).

Table No 1: Demographic data of participants

\begin{tabular}{|c|c|c|c|}
\hline Parameter & Cases & Controls & P value \\
\hline Age $($ years $)$ & $38.3 \pm 4.2$ & $36.51 \pm 3.54$ & 0.0795 \\
\hline Height $(\mathrm{cm})$ & $156.42 \pm 12.36$ & $158.21 \pm 14.58$ & 0.6099 \\
\hline Weight $(\mathrm{kg})$ & $67.24 \pm 8.53$ & $68.21 \pm 6.58$ & 0.6238 \\
\hline
\end{tabular}

Data was presented as mean $\pm \mathrm{SD}$. ( ${ }^{*} \mathrm{P}<0.05$ is significant, ${ }^{* *} \mathrm{P}<0.01$ is significant, ${ }^{* * *} \mathrm{P}<0.001$ is significant). Demographic data was not significant between cases and controls.

Table No 2: Visual acuity in cases and controls.

\begin{tabular}{|c|c|c|}
\hline Visual acuity & $\begin{array}{c}\text { Cases (n=30) (frequency \& } \\
\text { Percentage) }\end{array}$ & $\begin{array}{c}\text { Controls (n=30) (frequency \& } \\
\text { Percentage) }\end{array}$ \\
\hline $20 / 20$ & $0(0 \%)$ & $5(16.66 \%)$ \\
\hline $20 / 30$ & $0(0 \%)$ & $15(50 \%)$ \\
\hline $20 / 40$ & $3(10 \%)$ & $2(6.6 \%)$ \\
\hline $20 / 50$ & $1(3.33 \%)$ & $1(3.33 \%)$ \\
\hline $20 / 60$ & $8(26.66 \%)$ & $1(3.33 \%)$ \\
\hline $20 / 70$ & $2(6.66 \%)$ & $1(3.33 \%)$ \\
\hline $20 / 80$ & $6(20 \%)$ & $4(13.33 \%)$ \\
\hline $20 / 90$ & $3(10 \%)$ & $0(0 \%)$ \\
\hline $20 / 100$ & $6(20 \%)$ & $1(3.33 \%)$ \\
\hline $20 / 160$ & $1(3.33 \%)$ & $0(0 \%)$ \\
\hline
\end{tabular}

Data was expressed as frequency and percentage. Decline in the visual acuity was more prevalent in cases when compared to controls. 


\section{Discussion}

A set of hereditary retinal diseases characterized by the rod and cone photoreceptors degeneration is termed as Retinitis pigmentosa (RP). About 1 in 4000 is the prevalence of RP wherein a million of individuals are affected worldwide. The disease is inherited and can be inherited as X-linked trait (Approximately $5-15 \%$ of the cases), autosomaldominant (30- $40 \%$ ) or autosomal-recessive (50$60 \%)[9,10,11]$.

A study conducted in Japan reported that RP is the major cause for visual blindness. The study showed that $25 \%$ of the patients suffering with visual problems were due RP [12]. A similar result was noted in a study conducted in Kuwait, stating RP as a major leading cause of visual disability in the individuals less than 60 years of age [13]. A study in Denmark accounted blindness in around $29 \%$ of the cases between the age group 20-64years and learnt that the leading causes for blindness were retinitis pigmentosa and optic neuropathy [13].

Symptomatic vision loss is noted in few patients in childhood whereas few remain unsymptomatic until midadulthood. It is observed that there will be the loss of midperipheral visual field at young followed by gradual decrease of far peripheral vision and finally lead to the loss of central vision. Loss of night vision is often unnoticed as the work at night is done under sufficient light and using of spectacles also helps in proper vision.

1 in every 4000 are affected with retinitis pigmentosa, this is the worldwide prevalence. The disease may be X-linked inherited (5-15\%) or autosomal dominant $(30-40 \%)$ or autosomal recessive $(50-60 \%)[14,15,16]$. A study conducted in Kuwait, stated that retinitis pigmentosa is the most common cause for visual disability in individuals with less than 60 years [17]. A study in Denmark, accounted $29 \%$ of the cases related to blindness is due to retinitis pigmentosa whereas, Japan accounted $25 \%$ of the cases between 20 to 60 years of age $[18,19]$. The disease usually confined to eye, but found that about $20-40 \%$ of the cases can be associated as non-ocular disease i.e; the disease is associated with hearing impairment (Usher's syndrome).. Retinitis pigmentosa when associated with obesity [20] hypogenitalism, polydactyly, renal disorders and cognitive impairment is known as Bardet-Biedl syndrome. The disease is highly variable, it develops symptomatic vision loss in patients in childhood and in some it may remain asymptomatic till midadulthood [21,22]. In adulthood most of them report difficulty with dark adaptation, night blindness and loss of mid-peripheral vision field further leading to tunnel vision, when untreated and by 60 years it may lead to complete loss of central vision too. Most of the retinitis pigmentosa forms show excess of loss of rod function than the reduction of cone sensitivity.

The reversal pattern may be occasionally seen which is termed as cone-rod degeneration [23]. In other forms there is an equal decline in rod and cone functioning. The most prominent and early symptoms of this disease is defective colour vision and loss of visual acuity. Typical signs would be difficulty in undertaking daily activities and impairment in reading and this is observed when there is a fall in visual acuity below $0.5(20 / 40)$ $[24,25]$.

The present study also showed that RP leads decrease in visual acuity. Researchers focus, efforts and interest on the therapeutic approaches for RP promises for the sophisticated treatments further in the coming 10 years.

\section{Conclusion}

We have observed decline in the visual acuity in the patients with retinitis pigmentosa. We recommend further detailed studies in this area.

Contributions: All the authors equally contributed in designing the study, collection of data, analysis and interpretation and writing the article.

Funding: Nil, Conflict of interest: Nil

Permission from IRB: Yes

\section{References}

1. Hartong DT, Berson EL, Dryja TP. Retinitis pigmentosa. Lancet. 2006 Nov 18; 368 (9549): 1795-809.

2. Regan D, Neima D. Low-contrast letter charts as a test of visual function. Ophthalmology. 1983 Oct; 90 (10):1192-200. 


\section{Original Research Article}

3. Maho Oishi, Hajime Nakamura, Masanori Hangai, Akio Oishi, Atsushi Otani, and Nagahisa Yoshimura. Contrast visual acuity in patients with retinitis pigmentosa assessed by a contrast sensitivity tester. Indian J Ophthalmol. 2012; 60(6): 545-549.

4. Alexander KR, Derlacki DJ, Fishman GA. Visual acuityvslettercontrast sensitivity in retinitis pigmentosa. Vision Res. 1995 May;35 (10):1495-9.

5. Oomachi K, Ogata K, Sugawara T, Hagiwara A, Hata A, Yamamoto S. Evaluation of contrast visual acuity in patients with retinitis pigmentosa. Clin Ophthalmol. 2011;5:1459-63. doi: 10.2147/OPTH. S23070. Epub 2011 Oct 11.

6. Spellman DC, Alexander KR, Fishman GA, Derlacki DJ. Lettercontrast sensitivity in retinitis pigmentosa patients assessed by Regan charts. Retina. 1989;9(4):287-91.

7. Alexander KR, Derlacki DJ, Fishman GA. Contrastthresholds for letteridentification in retinitis pigmentosa. Invest Ophthalmol Vis Sci. 1992 May;33(6):1846-52.

8. A Datta,N Bhardwaj, SR Patrikar,and R Bhalwar. Study of Disorders of Visual Acuity among Adolescent School Children in Pune. Med J Armed Forces India. 2009; 65 (1): 26-29.

9. Bunker $\mathrm{CH}$, Berson EL, Bromley WC, Hayes RP, Roderick TH. Prevalence of retinitis pigmentosa in Maine. Am J Ophthalmol. 1984 Mar; 97 (3):357-65.

10. Novak-Lauš K, Suzana Kukulj S, Zoric-Geber M, Bastaic O. Primary tapetoretinal dystrophies as the cause of blindness and impaired vision in the republic of Croatia. Acta Clin Croat. 2002; 41(1): 23-27.

11. Grøndahl J. Estimation of prognosis and prevalence of retinitis pigmentosa and Usher syndrome in Norway. Clin Genet. 1987 Apr;31 (4): 255-64.

12. Hata H, Yonezawa M, Nakanishi T, Ri T, Yanashima K. Causes of entering institutions for visually handicapped persons during the past fi fteen years.Jpn J Clin Ophthalmol.2003;57:259-62.

13. Buch H, Vinding T, La Cour M, Appleyard M, Jensen GB, Nielsen NV. Prevalenceandcauses of visual impairment and blindness among 9980 Scandina vianadults: the Copenhagen City Eye Study. Ophthalmology. 2004 Jan; 111 (1): 53-61.

14. Bunker CH, Berson EL, Bromley WC, Hayes RP, Roderick TH. Prevalence of retinitis pigmentosa in Maine. Am J Ophthalmol. 1984 Mar; 97 (3):357-65.

15. Grøndahl J. Estimation of prognosis and prevalence of retinitis pigmentosa and Usher syndrome in Norway. Clin Genet. 1987 Apr;31 (4): 255-64.

16. Novak-Lauš K, Suzana Kukulj S, Zoric-Geber M, Bastaic O. Primary tapetoretinal dystrophies as the cause of blindness and impaired vision in the republic of Croatia. Acta Clin Croat2002;41:23-27.

17. Al-Merjan JI, Pandova MG, Al-Ghanim M, AlWayel A, Al-Mutairi S. Registered blindness and low vision in Kuwait. Ophthalmic Epidemiol. 2005 Aug; 12(4):251-7.

18. Buch H, Vinding T, La Cour M, Appleyard M, Jensen GB, Nielsen NV. Prevalenceandcauses of visual impairment and blindness among $9980 \mathrm{~S}$ candina vianadults: the Copenhagen City Eye Study. Ophthalmology. 2004 Jan; 111 (1): 53-61.

19. Hata H, Yonezawa M, Nakanishi $T$, Ri $T$, Yanashima K. Causes of entering institutions for visually handicapped persons during the past fi fteen years. Jpn J Clin Ophthalmol 2003; 57: 259-62.

20. Pennings RJ, Fields RR, Huygen PL, Deutman AF, Kimberling WJ, Cremers CW.Usher syndrome type III can mimic other types of Usher syndrome. Ann Otol Rhinol Laryngol 2003; 112: 525-30.

21. Tieder M, Levy M, Gubler MC, Gagnadoux MF, Broyer M. Renal abnormalities in the BardetBiedl syndrome. Int J Pediatr Nephrol. 1982 Sep;3 (3): 199-203. 
22. Beales PL, Elcioglu N, Woolf AS, Parker D, Flinter FA. New criteria for improved diagnosis of Bardet-Biedl syndrome: results of a population survey. J Med Genet 1999; 36: 437-46.

23. Birch DG, Anderson JL, Fish GE. Yearlyrates of rod and conefunctionalloss in retinitis pigmentosa and cone-rod dystrophy. Ophthalmology. 1999 Feb;106(2):258-68.
24. Grover S, Fishman GA, Anderson RJ, Tozatti MS, Heckenlively JR, Weleber RG, Edwards AO, Brown J Jr. Visual acuityimpairment in patients with retinitis pigmentosa at age 45 years or older. Ophthalmology. 1999 Sep;106(9):1780-5.

25. Virgili G, Pierrottet C, Parmeggiani F, et al. Reading performance in patients with retinitis pigmentosa: a study using the MNREAD charts. Invest Ophthalmol Vis Sci 2004; 45: 3418-24.

\section{How to cite this article?}

Alruwaili I.Y, Vanishri A, Ashok Kumar.Visual acuity in patients with retinitis pigmentosa. Trop J Ophthalmol Otolaryngol.2017;2(1):1-5. doi: 10.17511/jooo.2017.i01.01. 